Rijnders, M., Offerhaus, P., Dommelen, P. van, Wiegers, T., Buitendijk, S. Prevalence, outcome, and women's experiences of external cephalic version in a low-risk population. Birth: 2010, 37(2), 124-133

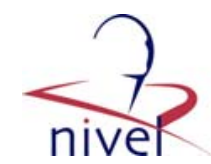

\begin{tabular}{|l|l|}
\hline Postprint Version & 1.0 \\
\hline Journal website & $\underline{\text { http://onlinelibrary.wiley.com/doi/10.1111/j.1523-536X.2010.00392.x/abstract }}$ \\
\hline Pubmed link & $\underline{\text { http://www.ncbi.nlm.nih.gov/pubmed/20557535 }}$ \\
\hline DOI & $10.1111 / \mathrm{j} .1523-536 X .2010 .00392 . x$
\end{tabular}

This is a NIVEL certified Post Print, more info at http://www.nivel.eu

\title{
Prevalence, Outcome, and Women's Experiences of External Cephalic Version in a Low-Risk Population
}

\author{
Marlies RiJnders, RM, Pien Offerhaus, MSc, RM, Paula VAn Dommelen, PhD, Therese \\ WIEGERS, PHD, AND SIMONE BUITENDIJK, MD, MPH, PHD
}

Marlies Rijnders is a research midwife, Paula van Dommelen is a statistician, and Simone Buitendijk is a perinatal epidemiologist at TNO Quality of Life in Leiden and Professor of Midwifery Studies at the Academic Medical Center of the University of Amsterdam (AMC); Pien Offerhaus is a midwife and staff member of the Royal Dutch Association of Midwives (KNOV); and Therese Wiegers is a psychologist and epidemiologist at the Netherlands Institute for Health Services Research (NIVEL), The Netherlands.

This study was funded by the Royal Dutch Association of Midwives, Utrecht, The Netherlands.

\begin{abstract}
Background: Until recently, external cephalic version to prevent breech presentation at birth was not widely accepted. The objective of our study was to assess the prevalence, outcomes, and women's experiences of external cephalic version to improve the implementation of the procedure in the Netherlands. Methods: A prospective cohort study was conducted of 167 women under the care of a midwife with confirmed breech presentation at a gestational age of 33 completed weeks or more. Results: Between June 2007 and January 2008, 167 women with a confirmed breech presentation were offered an external cephalic version. Of this group, 123 women (73.7\%, 95\% CI: 65.5-80.5) subsequently received the version. These women had about a ninefold increased probability of a cephalic presentation at birth compared with women who did not undergo a version (relative risk [RR]: 8.8, 95\% CI: 2.2-34.8). The chance of a vaginal birth after an external cephalic version was almost threefold (RR: 2.7, 95\% CI: 1.5-5.0). The success rate was 39 percent, although considerable differences existed associated with region and parity. Ninety-four percent of women with a successful version rated it as a good experience compared with 71 percent of women who had a failed version ( $\mathrm{p}$ $=0.015$ ). Significant pain during the version was experienced by 34 percent of women, of whom 18 percent also experienced fear during the version, compared with no women who reported little or no pain $(\mathrm{p}=0.006)$. Women who reported significant pain or fear during the version experienced the version more negatively (OR: 6.0, 95\% CI: 3.3-12.2 and OR: 2.7, 95\% CI: 1.1-6.0, respectively). Conclusions: One in every four women with a breech presentation in independent midwifery care did not receive an external cephalic version. Of the women who received a version one third experienced significant pain during the procedure. Considerable regional variation in success rate existed.
\end{abstract}

Until recently, external cephalic version to prevent breech presentation at birth was not widely accepted. In the Netherlands, obstetricians, and to a lesser extent midwives, considered the procedure an 
Rijnders, M., Offerhaus, P., Dommelen, P. van, Wiegers, T., Buitendijk, S. Prevalence, outcome, and women's experiences of external cephalic version in a low-risk population. Birth: 2010, 37(2), 124-133

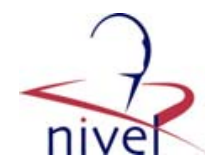

inefficient and potentially risky intervention for the baby (1-3). As a result, it was not offered systematically to all women with breech presentation at term $(4,5)$, and vaginal breech birth was relatively common. After publication of the Term Breech Trial in 2000 (6), the cesarean section rate for breech presentation increased from 50 to 80 percent in 2001 in the Netherlands $(7,8)$. The rise in cesareans for breech presentation renewed the interest in external cephalic version (9), and a reevaluation of available evidence indicated that this procedure was a safe and effective intervention (10-16). It was introduced into Dutch National Guidelines by the Royal Dutch Association of Midwives (17) and the Dutch Association of Obstetricians and Gynaecologists (18) in 2001 and 2002.

In the Netherlands, a distinction is being made within the maternity care system between women with a low risk and those with a high risk of complications. Most women enter maternity care at the primary care level, and early pregnancy care is delivered by an independently practicing midwife. If pregnancy, childbirth, and the postpartum period are uncomplicated, the woman remains under the care of the midwife. If complications occur or threaten to occur, the midwife refers the woman to an obstetrician.

Breech presentation at term is an indication for referral to an obstetrician (19), and an external cephalic version may be offered and performed in secondary care.

However, a version can also be performed by the primary care midwife (20). In the Netherlands, 93 percent of all midwives refer to an obstetrician for a version (4).

When the procedure is successful, the woman returns to her own midwife for the remaining prenatal and perinatal care.

At present, 94 percent of Dutch midwives (21) and 92 percent of all obstetricians (5) state that they offer women the option for a version. The reported incidence of external cephalic versions in the Dutch Perinatal Registry ranges from 0.21 to 0.25 percent of all pregnancies (22). As the prevalence of breech presentations at term is approximately 3 percent, versions are either underreported or infrequently performed. Analyses of data of the Dutch Perinatal Registry with respect to presentation at birth show that since the introduction of the aforementioned guidelines in 2001 and 2002, the numbers of vaginal breech birth at term remain stable, implying a low implementation or a low success rate of external cephalic version.

The objective of our study was, first, to assess the prevalence and outcomes of external cephalic version to improve the implementation of the procedure in the Netherlands. Second, to gain more insight into the barriers to this procedure, we studied the reasons presented by women and practitioners for not undergoing or performing a version, respectively $(23,24)$. The perceived low success rate, perceived lack of safety, and concerns about pain during the version are also known to be the reasons for decline $(23,25)$. Therefore, third, as secondary outcomes in this study we explored factors that may influence women's experience with a version such as pain, success rate, receipt of counseling, and medication.

\section{METHODS}

\section{Design}

A prospective cohort study was undertaken to identify the prevalence of external cephalic version among women with breech presentation receiving prenatal care in a representative sample of independent midwifery practices. The study was carried out between June 2007 and January 2008.

All women with suspected breech presentation at a gestational age of 33 completed weeks or more were identified by their midwife and reported to the research team on a weekly basis using questionnaires. In the case of incomplete data on offer and performance of an external cephalic version, active follow-up was performed by weekly telephone contact with the midwifery practices.

The midwife collected data on the basic characteristics of all women with a suspected breech presentation. After confirmation of breech presentation, more detailed questionnaires were provided to the women, the primary midwife, and the caregiver who was to perform the version.

The questionnaires included multiple choice questions and some open-ended questions that addressed procedures and outcomes, possible explanations for decline or nonperformance of the version, women's experiences, and the outcome and mode of birth.

Women were asked to complete the questionnaire after the version but before the birth to prevent recall bias by mode of birth. Pain and fear during the version were measured separately on a five-point scale with the following response options: "extreme pain (respectively fear)"; " a lot of pain (respectively fear)"; " "pain (respectively fear)"'; "little pain (respectively fear)"; and "no pain at all (respectively fear).' For 
Rijnders, M., Offerhaus, P., Dommelen, P. van, Wiegers, T., Buitendijk, S. Prevalence, outcome, and women's experiences of external cephalic version in a low-risk population. Birth: 2010, 37(2), 124-133

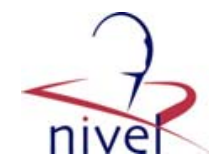

data analyses, the first three categories were formed into one category "yes" pain (respectively fear) and the last two categories were formed into one category "no"” pain (respectively fear).

The outcome variable "experience with ECV" "was also measured on a five-point scale with the following response options: "very positive experience”; " "positive experience”; " no positive or negative experience”; " "negative experience”; and "very negative experience.” For data analyses, the last two categories were formed into one category " "negative experience" because of the low numbers of women in the category "very negative experience."

\section{Sample Size}

Midwifery practices in the Netherlands differ in size.

Based on the number of midwives in a practice, we estimated an average annual practice size. A practice with one full-time working midwife is expected to provide care to an average of 110 women. Accordingly, a middle and large practice with two and three, respectively, or more midwives was estimated to have corresponding practice sizes of 240 or 360 and more women.

Based on data from the Dutch Perinatal Registry, we assumed a prevalence of breech presentation of 2.2 percent at 34 weeks of gestation among our specific study population of low-risk women receiving prenatal care by an independent midwife $(17,22)$. We assumed that 50 percent of women with a confirmed breech presentation would receive an external cephalic version. To estimate a point prevalence performance of the version plus or minus 7.5 percent with a 95\% confidence interval (CI), 162 pregnant women with confirmed breech presentation were needed to be included tolerating a reasonable sample error with a feasible sample size. To be able to register 162 women with confirmed breech presentation, 39 midwifery practices had to participate during a period of 6 months. A stratified sample was drawn based on practice size (i.e., the number of midwives per practice) per region (north, central, and south; 26).

As we assumed a participation rate of 60 percent, a sample size of 65 midwifery practices were selected.

The sampling frame was constructed by the Netherlands Institute for Health Services Research. Midwifery practices were approached by mail for participation. If a practice declined, the reason for nonparticipation was registered.

\section{Data Analysis}

The chi-square test was used to compare proportions and analysis of variance (ANOVA) was used to compare means between groups. Logistic regression analyses were used to predict pain during the version procedure.

Ordinal regression analysis using a probit link function was used to predict experience with the version (order response category variable). The link function specifies what transformation is applied to the dependent variable (i.e., experience with the version). A probit link function was used because the dependent variable was normally distributed. Risks were compared by calculating relative risks (RR) and 95 percent CIs (95\% CI). All statistical tests were two-tailed, and $\mathrm{p}<0.05$ were considered statistically significant. Data analyses were performed with SPSS Version 14.0 (27).

\section{RESULTS}

\section{Population}

Of the 65 midwifery practices approached, 49 (75\%) agreed to participate. The reasons cited for nonparticipation included "too busy"' (six practices), "involved in other research projects" (3), "we do not perform versions”, (2), "not practicing anymore”, (2), and "just started practicing”, (1). Of the 49 participating midwifery practices, 3 never returned any data despite active follow-up. Therefore, data of 46 midwifery practices were analyzed. No statistical differences were identified in region or caseload between approached and actual participating midwifery practices or between number of actual confirmed breech presentation and expected numbers (data not shown).

Table 1 shows the characteristics of all women with a suspected breech presentation during the study period.

Compared with the National Perinatal Registry that contains data on all pregnant women in 2005, our sample had significantly more ethnically Dutch women. Other demographic variables did not differ 
Rijnders, M., Offerhaus, P., Dommelen, P. van, Wiegers, T., Buitendijk, S. Prevalence, outcome, and women's experiences of external cephalic version in a low-risk population. Birth: 2010, 37(2), 124-133

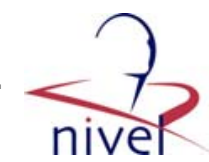

significantly. Most of (suspected) the breech presentations were diagnosed before 36 weeks' gestation, and most versions were performed after 37 weeks of pregnancy.

\section{Performance of External Cephalic Version}

Figure 1 shows the course of all pregnancies with confirmed breech presentation including their birth outcomes.

All women with suspected breech were referred to an obstetrician for an external cephalic version in 41 different hospitals. One version was performed in a midwifery practice, without success. The flow chart shows that 73.7 percent (95\% CI: 65.5-80.5) of women with a confirmed breech presentation received a version. Of the 44 women (26\%) who did not receive a version, reasons were known for 42 women. Of these, 15 women (37\%) did not want a version, 7 gave birth before the version was performed, and for 20 (48\%) the obstetrician decided not to perform it. Reasons stated for not performing a version were "logistic reasons," such as breech detected during birth, premature birth before planned version; "reasons given by women' to decline version, such as perceived high risk, low success rate, negative stories from others; and "reasons given by professionals,"' such as not enough amniotic fluid or tight abdominal muscles, breech engaged, placenta anterior (not low), child small for gestational age or with congenital malformation(s), unstable lie, low umbilical cord, and previous cesarean section. Receiving a version did not differ significantly with respect to region, midwifery caseload, or women's parity, background, or age (data not shown). However, if a breech presentation was detected before 37 weeks, 78 percent of the women received a version $(n=107 / 138)$ versus 50 percent if a breech presentation was detected after 37 weeks $(n=11 / 22$; $\mathrm{p}=0.006)$.

\section{[FIGURE 1]}

\section{[TABLE 1]}

\section{Procedure}

In 85 percent of the women the number of version attempts carried out to achieve a cephalic presentation, was registered, but not whether these attempts had been done in one or more sessions. More then one attempt was recorded in one-third of the women (36/105). In 108 women (88\%), use of medication during the version was recorded. In the recorded cases, 37/108 (37\%) of the women received tocolytic medication. No records were available about the use of pain relief during the version, which most likely indicated it was not actually used. The use of medication was significant in the north (12\%) compared with the central (36\%) and south regions (51\%; $\mathrm{p}<0.001)$.

\section{Complications}

Four minor complications were recorded. Three fetuses had bradycardia lasting less than 10 minutes, two after a successful and one after a failed version. On ultrasound examination, a low umbilical cord was detected in one fetus that resolved spontaneously after 1 day. All four newborns were born vaginally and in good condition.

\section{Success Rate}

The success rate of external cephalic version was 39 percent.

No significant differences were seen in success rate among women with respect to their educational level, age, or ethnicity (data not shown). Furthermore, the size of midwifery practice, number of versions performed per hospital, duration of pregnancy at the time of breech detection or the performance of the version, or the use of tocolysis was not associated with significant differences in success rate (data not shown).

As expected, a significant difference occurred in success rate by parity: nulliparas had a lower success rate compared with multiparas: 27 percent $(n=18 / 66)$ versus 57 percent $(n=26 / 46 ; p=0.002)$. 
Rijnders, M., Offerhaus, P., Dommelen, P. van, Wiegers, T., Buitendijk, S. Prevalence, outcome, and women's experiences of external cephalic version in a low-risk population. Birth: 2010, 37(2), 124-133

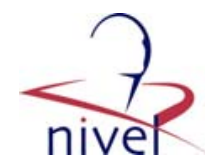

Furthermore, considerable differences existed among the three regions of midwifery practices in the Netherlands.

The south region had a success rate of 16 percent (5/32) compared with 42 percent (20/48) in the central region, and 54 percent $(23 / 43)$ in the north $(\mathrm{p}=0.004)$.

The success rate in the south remained significantly lower for multiparas, that is, 11 percent versus 67 percent in the north and 69 percent in the central region $(\mathrm{p}=0.006)$. For nulliparas, the success percentage in the south was 14 percent compared with 39 percent in the north and 31 percent in the central region. The difference was not significant. The adjusted odds ratios (parity and region) for failed versions were 5.5 (95\% CI: 1.6- 19.2) for the south region compared with the north region, and 3.1 (95\% CI: 1.3-7.2) for nulliparas compared with multiparas. The lower success rate in the south could partially be ascribed to one hospital where 16 women with confirmed breeches were referred. A version was performed in 11 women, but none was successful.

However, even after exclusion of this particular hospital, the success rate of 20 percent $(4 / 20)$ in the south remained significantly lower $(p=0.04)$ than that of the other two regions.

Women who received a version had an almost ninefold increased probability of a cephalic presentation at birth compared with women who did not receive the procedure, $\mathrm{RR}=8.8$ (95\% CI: 2.2-34.8). The chance of a vaginal birth was almost threefold (RR: 2.7, 95\% CI: 1.5-5.0).

\section{Experiences of Women}

The questionnaire response rate of women who received a version was 80 percent $(97 / 123)$ compared with 93 percent $(41 / 44)$ of those who did not receive it. Information about external cephalic version was provided to 93 percent of the women, more frequently to those who actually received one (96\%) than to those who did not $(85 \%$; $\mathrm{p}=0.06)$. The information was provided verbally $(88 \%)$, by information leaflet (53\%), and/or by referral to a website (15\%).

Women who had received a version were asked to score the counseling by their midwife and the performer of the version. Six percent thought that the counseling at the time of breech detection by their own midwife had been very poor, whereas 23 percent considered it to be adequate and 71 percent good or very good. Counseling by the version's performer (in all but one case an obstetrician) provided at the time of confirmation of presentation or performance was rated poor by 3 percent, adequate by 9 percent, and good or very good by 87 percent of the women. Counseling scores were not associated with success rate or region (data not shown).

Of the 37 (37\%) women who received tocolysis, 13 (37\%) said it was unpleasant, 19 (54\%) were neutral, and $3(9 \%)$ were positive.

Most women (55\%) were neutral about the fact they had to go to hospital for a version, 7 percent found it unpleasant, and 38 percent experienced it as pleasant.

Most women were positive about the fact they had received an ultrasound examination (94\%) and fetal monitoring (84\%) during the procedure.

Sixty-eight percent of women (65/95) stated that the experience of a version was, by and large, as they had expected, and of those 83 percent (54/65) considered it to be a good experience. Of the 32 percent (30/ 95) who stated that it had not been as they had expected, 67 percent $(20 / 30)$ said that it had been a good experience. Of the women with a successful version, 94 percent $(30 / 32)$ rated the intervention as a good experience compared with 71 percent $(45 / 63)$ of women with a failed version $(\mathrm{p}=0.015)$.

Eleven percent (10/95) of the women who received a version said they experienced no pain at all during the procedure, 30 percent (28/95) experienced little pain, 34 percent (32/95) experienced pain, 17 percent (16/95) experienced a lot of pain, and 10 percent (9/95) experienced extreme pain. After dichotomizing pain levels into “no pain or a little pain” versus “pain, a lot of pain, or extreme pain,'” factors significantly associated with the latter were success, region, and diagnosis before 36 completed weeks of pregnancy. Parity, performance before 36 completed weeks, or tocolysis were not associated with pain levels (data not shown).

\section{[TABLE 2] [TABLE 3]}


Rijnders, M., Offerhaus, P., Dommelen, P. van, Wiegers, T., Buitendijk, S. Prevalence, outcome, and women's experiences of external cephalic version in a low-risk population. Birth: 2010, 37(2), 124-133

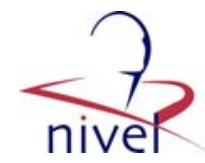

Table 2 shows the adjusted odds ratios for those factors that, after univariate analysis, were significantly associated with pain during the version. Women who received a version in the south or central region compared with the north or women who had a failed version, had an increased chance of experiencing pain, a lot of pain, or extreme pain.

One-third (33\%) of the women who expressed fear before the version also experienced fear during the version compared with 7 percent of the women who had no fear before the version $(44 / 76 ; p=0.006)$. However, no significant relationship between fear before the version and pain during the version existed. Sixty-seven percent of the women who expressed fear before the version experienced pain compared with 58 percent of the women without fear before the version. On the other hand, all women who experienced fear during the version experienced significant pain $(n=11)$ compared with 55 percent $(46 / 84)$ of the women who did not experience fear during the version $(\mathrm{p}=0.003)$. All women who rated the counseling as poor $(n=7)$ experienced significant pain compared with 57 percent $(50 / 88)$ of the women who rated the counseling as good. Poor counseling was not associated with expressed fear before or during the version Furthermore, after ordinal regression, pain and fear during the version significantly increased the probability of women rating their experience negatively. The adjusted odds ratio for women having had pain to rate their experience more negatively was 6.0 (95\% CI: 3.3-12.2) compared with women who had no or little pain.

No woman who had experienced fear during the version rated the experience as (very) positive. The adjusted odds ratio to rate their experience more negatively was 2.7 (95\% CI: 1.1-6.0; Table 3). The explained variance (Nagelkerke $\mathrm{R}^{2}$ ) for this model was 54 percent.

\section{DISCUSSION}

All women in this study were offered an external cephalic version by their midwife and were subsequently referred. Seventy-three percent of these women accepted the offer. This rate is comparable with that reported in other populations $(23,25,28)$. It is also in concordance with the claim of 94 percent of the Dutch midwives that they offer a version to all their pregnant women with suspected breech at term (21).

However, 26 percent of all women in our study did not receive a version. It has been shown that the acceptance rate varies significantly according to the health professional offering the procedure (29). The reasons given in our study for not performing a version suggest there is room for improvement. The most frequently mentioned unfavorable clinical factors were "not enough amniotic fluid" or "tight abdominal muscles" and "breech engaged." In a vignette study among Dutch obstetricians these reasons were found to explain 80 percent of the decisions not to perform a version (30).

Oligohydramnios is perceived as a relative contraindication (31). Insufficient amniotic fluid and engagement of breech as decisional factors not to perform an external cephalic version, however, are not evidence-based contraindications.

In this study, no absolute contraindications were stated. The indications " low umbilical cord," " anterior placenta," and "previous cesarean section"' are not considered to be contraindications according to national and international guidelines (18,31). Furthermore, major differences were observed in actual performance and in success rates among regions, suggesting that further implementation of external cephalic version should not only address the improvement of competencies to perform the procedure but should also focus on more adequate evidence-based decision making.

The willingness of women in our study to accept a version appears higher than that reported elsewhere. Only 15 women, 9 percent of all women with confirmed breech, did not want it. Reported rates of maternal refusal range from 18 to 76 percent $(23,24,28)$, although over 90 percent of the women reportedly preferred a vaginal birth rather than a cesarean $(24,29,32)$. In an Australian study 39 percent of the women responded that they would not choose a version, another 39 percent would, and the remaining 22 percent were uncertain (23). A similar study from Israel in 1999 reported that more than half of the women (53\%) had heard of a version, and 54 percent were willing to consider it, whereas in 2001, 73 percent had heard of it but only 24 percent were willing to consider it (24). To our knowledge, only one United Kingdom study showed a comparable rate (65\%) of women with a breech presentation opting for a version (32).

Recently, studies have reported about women's attitude toward and knowledge of external cephalic version $(23,25,33)$ and about interventions to help them in their decision (34). The most frequently mentioned reasons for not having a version by women were "perceived risks" or "pain" and "perceived 
Rijnders, M., Offerhaus, P., Dommelen, P. van, Wiegers, T., Buitendijk, S. Prevalence, outcome, and women's experiences of external cephalic version in a low-risk population. Birth: 2010, 37(2), 124-133

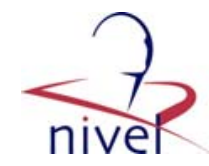

success rate.' In our study the chance of a child in cephalic presentation at birth and the chance of a vaginal birth increased significantly after a version, even with an average success rate of "only"' 39 percent. No major complications were reported in this study. Although the absence of complications in our study may partially be owing to its limited sample size, it has been shown in other studies that complications are rare and that a version can be considered to be a safe procedure $(10-12,14-16,35)$.

Improved counseling techniques and better dissemination of information to the women and their partners with more emphasis on the advantages and less on the risks seems justifiable.

However, pain is an aspect that should be emphasized more in counseling. Fok et al reported that a version without analgesia was associated with a moderate degree of pain (36). They measured pain on a visual analog scale (VAS) among 97 women and found a median score of 5.7 on a scale from 0 to 10 , where 0 was no pain at all and 10 was as severe a pain as imaginable. They concluded that the pain was well tolerated by pregnant women because of its short duration (36). In a Czech Republic study among 110 women, a mean value of 4.9 on a VAS scale was found and eight versions (7\%) were discontinued for reasons of pain (37).

In our study, which measured pain using five categorical levels, 60 percent of women experienced more than significant pain, and 25 percent even experienced a lot of pain. In the study by Fok et al, only 2 percent rated no pain, a score below 3 was found by 28 percent, and a score over 7 by 20 percent (36). In our study we had a higher rate of women reporting "no pain at all" (11\%), and the other rates were comparable with those found in the literature with 30 percent reporting a "little pain"' and 27 percent " a lot of pain." As in our study, pain during the version was related to success in other studies $(36,37)$ but not to parity. As in the study by Hutton et al, we did not find an association between pain and performance before or after 36 completed weeks of gestation (38). Women in the north reported significantly less pain compared with women in the two other regions after correction for time of diagnosis and success rate. This finding cannot be explained by other factors such as differences in time of performance, parity, counseling scores, or increased use of tocolytic medication. Therefore, we are as yet unable to understand the relationship between region and reported pain.

In our study no pain or just a little pain was associated with an overall positive appraisal. In agreement with the results of Hutton et al, most women (79\%) were willing to undergo a version in a subsequent pregnancy. In addition, in our study 80 percent of the women stated that the version had turned out to be better than expected.

However, women with a more negative experience were those who more likely had experienced pain, a lot of pain, or extreme pain or fear during the version.

\section{Limitations}

Our study was conducted among low-risk women receiving prenatal care in an independent midwifery practice. The high acceptance of an external cephalic version might be related to the target population studied.

A successful version results in women having the choice to receive the remaining perinatal care from their initial chosen caregiver and in a choice of place of birth. Therefore, the prevalence of offer, acceptance, and performance may not be completely generalized to other populations of pregnant women.

Although the sample was identified by an independent research institute and reasons for nonparticipation did not seem to have any association with acceptance of a version, it is still possible that the sample was not representative.

Significantly fewer non-Dutch women were entered into the study compared with the national population of pregnant women in 2005. However, other characteristics of pregnant women and the expected and actual numbers of participating practices and prevalence of breech presentations seem to indicate accurate sampling.

In our study only one version was performed by an independent midwife, although nationally the percentage is expected to be around 7 percent (4). In our sample the results are presented of women from 10 percent of all Dutch midwifery practices and 41 percent of all Dutch hospitals equally divided over the Netherlands.

We therefore expect our study population to be representative of low-risk women in the Dutch maternity system.

To assess the accuracy of estimated prevalence of offer and performance of external cephalic version, we undertook intensive weekly follow-up by telephone. We decided not to perform an extra check for 
Rijnders, M., Offerhaus, P., Dommelen, P. van, Wiegers, T., Buitendijk, S. Prevalence, outcome, and women's experiences of external cephalic version in a low-risk population. Birth: 2010, 37(2), 124-133

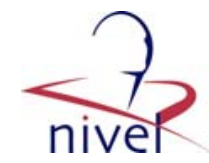

underreporting in the medical records, as it was unlikely this check would have yielded more complete results. Registration of versions in the medical records or in the Dutch Perinatal Registry is far from perfect $(4,5,17)$. One-third of the midwives report that they never register a version attempt in their medical record (4), and only 19 percent of the obstetric units have a formal registration of number and outcome of versions (5).

We designed a special short questionnaire to explore women's experiences with the version because no validated questionnaires on experience with this intervention exist. The results are intended to be explorative for future research and should be interpreted with caution.

The data collected among women who did not receive an external cephalic version are limited, and further research into the inhibiting and enhancing factors of receiving a (successful) version is needed. A recent Dutch study has already shown an improved success rate by using a specific protocol and limiting its performance to a small team (39).

\section{CONCLUSIONS}

External cephalic version is an important procedure for the prevention of breech presentation at birth and of subsequent cesarean section. The procedure appears to be safe and can increase the chances of a vaginal birth by a factor of two. Nevertheless, one in every four women with a breech presentation in independent midwifery care did not receive an external cephalic version. Women with a baby in breech presentation who are approaching term should be counseled on the importance of the procedure. They should also be prepared for experiencing some discomfort and pain during the procedure. Of the women who received a version, one third experienced significant pain during the procedure. Caregivers should be trained in the technique, as the chance of success appears to differ substantially among centers.

\section{ACKNOWLEDGMENTS}

The authors thank the participating women, midwives, and obstetricians. Without their help this study would not have been possible. The authors also thank D.J. Taylor for critically reviewing earlier drafts of this paper.

\section{REFERENCES}

1. Mensink WF, Huisjes HJ. Heeft de uitwendige kering bij stuitligging zin? Is external version useful in breech presentation? Ned Tijdschr Geneeskd 1980;124(43):1828-1831.

2. Treffers P. De uitwendige versie bij stuitligging [ECV for breech presentation]. Tijds Verloskd 1998;23(7/

8):2-5.

3. van der Pavert R, Bennebroek GJ, Keirse MJ. Het nut van de uitwendige versie bij stuitligging a terme [The benefit of external version in full-term breech presentation]. Ned Tijdschr Geneeskd 1990;134(46):2245-2248.

4. Beuckens $A$. De registratie en uitvoering van de uitwendige versie [Registration and performance of ECV]. Tijds Verloskd 2007;32(7/8):22-24.

5. Feitsma AH, Middeldorp JM, Oepkes D. De uitwendige versie bij de a terme stuit: een inventariserend onderzoek [External cephalic version at term; an inventarisation]. Ned Tijds Obstet Gynaecol 2007;120:46.

6. Hannah ME, Hannah WJ, Hewson SA. Planned caesarean section versus planned vaginal birth for breech presentation at term: A randomised multicentre trial. Lancet 2000;356:1375-1383.

7. Rietberg CC, Elferink-Stinkens PM, Brand R, et al. Term breech presentation in the Netherlands from 1995 to 1999: Mortality and morbidity in relation to the mode of delivery of 33824 infants.

BJOG 2003;110(6):604-609.

8. Molkenboer JF, Bouckaert PX, Roumen FJ. Recent trends in breech delivery in the Netherlands. BJOG 2003;110(10):948-951.

9. Shennan A, Bewley S. How to manage term breech deliveries.

BMJ 2001;323(7307):244-245.

10. Collaris RJ, Oei SG. External cephalic version: A safe procedure? A systematic review of versionrelated risks. Acta Obstet Gynecol Scand 2004;83(6):511-518.

11. Collins S, Ellaway $P$, Harrington $D$, et al. The complications of external cephalic version: Results from 805 consecutive attempts.

BJOG 2007;114(5):636-638. 
Rijnders, M., Offerhaus, P., Dommelen, P. van, Wiegers, T., Buitendijk, S. Prevalence, outcome, and women's experiences of external cephalic version in a low-risk population. Birth: 2010, 37(2), 124-133

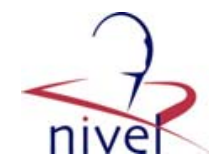

12. Hofmeyr GJ, Kulier R. External cephalic version for breech presentation at term. Cochrane Database Syst Rev 2006;25(1):CD000084.

13. Kok M, Cnossen J, Gravendeel L, et al. Clinical factors to predict the outcome of external cephalic version: A meta analysis. Am J Obstet Gynecol 2008;199(6):630-637.

14. Nassar N, Roberts CL, Barratt A, et al. Systematic review of adverse outcomes of external cephalic version and persisting breech presentation at term. Paediatr Perinat Epidemiol 2006;20(2):163-171.

15. Rijnders M, Herschderfer K, Prins M, et al. A retrospective study of the success, safety and effectiveness of external cephalic version without tocolysis in a specialised midwifery centre in the Netherlands. Midwifery 2006;24(1):38-45.

16. Grootscholten K, Kok MD, Post van der J, et al. External cepahlic version: A meta-analysis. Obstet Gynecol 2008;112(5):1143- 1151.

17. Verburgt T, Offerhaus PM. KNOV standpunt uitwendige versie [Guideline ECV]. Bilthoven, The Netherlands: Royal Dutch Association of Midwives, 2006.

18. Kleiverda G, Lambers MDA. NVOG richtlijn "stuitligging" (2.1) [Guideline Breech and ECV]. Dutch Association for Obstetrics and Gynaecology, 2006. Accessed November 25, 2009. Available at: http://nvog-documenten.nl/index.php?pagina=/richtlijn/pagina.

php\&fSelectTG_62=75\&fSelectedSub=62\&fSelectedParent $=75$.

19. Commissie Verloskunde van het College voor zorgverzekering.

Verloskundig Vademecuum 2003 [Dutch Obstetric Manual]. Diemen, The Netherlands: College voor Zorgverzekering, 2003.

20. Borst-Eilers E, Sorgdrager W. Besluit opleidingseisen en deskundigheidsgebied verloskundige [Resolution Training and Competences in Midwifery Education]. Den Haag, The Netherlands: Lexius, 1997.

21. Beuckens A. De voorlichting over de uitwendige versie [Counseling ECV]. Tijds Verloskd 2007;32(6):23-24.

22. Brouwers HAA, Bruinse HW, Huis van AM, Miranda de E. Perinatale zorg in Nederland 2005 [Perinatal

Care in the Netherlands 2005]. Zutphen, The Netherlands: Tesink, 2008.

23. Leung TY, Lau TK, Lo KW, Rogers MS. A survey of pregnant women's attitude towards breech delivery and external cephalic version. Aust N Z J Obstet Gynaecol 2000;40(3):253-259.

24. Yogev $Y$, Horowitz E, Ben-Haroush A, et al. Changing attitudes toward mode of delivery and external cephalic version in breech presentations. Int J Gynaecol Obstet 2002;79(3):221-224.

25. Caukwell S, Joels LA, Kyle PM, Mills MS. Women's attitudes towards management of breech presentation at term. J Obstet Gynaecol 2002;22(5):486-488.

26. Wiegers TA, Janssen BM. Monitor verloskundige zorgverlening: Eindrapport [Monitoring Maternity Care: Final Report]. Utrecht, The Netherlands: NIVEL, 2006.

27. SPSS Inc. SPSS 14.0 Inc [computer program], Version 14.0. Chicago, IL: SPSS Inc, 2007.

28. Bewley S, Robson SC, Smith M, et al. The introduction of external cephalic version at term into routine clinical practice. Eur J Obstet Gynecol Reprod Biol 1993;52(2):89-93.

29. Johanson R, Burr R, Leighton N, Jones P. Informed choice? Evidence of the persuasive power of professionals. J Public Health Med 2000;22(3):439-440.

30. Kok M, Van Der Steeg JW, Mol BW, et al. Which factors play a role in clinical decision-making in external cephalic version? Acta Obstet Gynecol Scand 2008;87(1):31-35.

31. Green Top Guideline No. 20a. External Cephalic Version and Reducing the Incidence of Breech Presentation. Royal College of Obstetricians and Gynecologists, 2006. Accessed November 25, 2009. Available at: http://www.rcog.org.uk/files/rcog-corp/ uploaded-files/GT20aExternalCephalica2006.pdf.

32. Chong ES, Mongelli M. Attitudes of Singapore women toward cesarean and vaginal deliveries. Int J Gynaecol Obstet 2003;80(2):189-194.

33. Raynes-Greenow $\mathrm{CH}$, Roberts $\mathrm{CL}$, Barratt $\mathrm{A}$, et al. Pregnant women's preferences and knowledge of term breech management, in an Australian setting. Midwifery 2004;20(2):181-187.

34. Nassar N, Roberts CL, Raynes-Greenow CH, et al. Evaluation of a decision aid for women with breech presentation at term: A randomised controlled trial [ISRCTN14570598]. BJOG 2007; 114(3):325-333.

35. Nassar N, Roberts CL, Cameron CA, Peat B. Outcomes of external cephalic version and breech presentation at term, an audit of deliveries at a Sydney tertiary obstetric hospital, 1997-2004. Acta Obstet Gynecol Scand 2006;85(10):1231- 1238.

36. Fok WY, Chan LW, Leung TY, Lau TK. Maternal experience of pain during external cephalic version at term. Acta Obstet Gynecol Scand 2005;84(8):748-751.

37. Nagy J, Nyklova E. Is fear of external cephalic version well-founded? Ceska Gynekol 2008;73(4):254260. 
Rijnders, M., Offerhaus, P., Dommelen, P. van, Wiegers, T., Buitendijk, S. Prevalence, outcome, and women's experiences of external cephalic version in a low-risk population. Birth: 2010, 37(2), 124-133

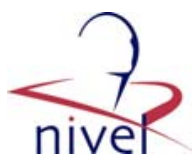

38. Hutton EK, Kaufman K, Hodnett E, et al. External cephalic version beginning at 34 weeks' gestation versus 37 weeks' gestation: A randomized multicenter trial. Am J Obstet Gynecol 2003;189(1):245-254. 39. Kuppens SM, Hasaart TH, van der Donk MW, et al. Minder keizersneden wegens stuitligging dankzij geprotocolleerde uitwendige versie in een speciaal spreekuur [Fewer caesarean sections for breech presentation following external cephalic version according to a protocol in a special office visit]. Ned Tijdschr Geneeskd 2008;152(23):1323-1328.

\section{TABLES AND FigURES}

Figure 1. Flow chart depicting numbers and outcomes of external cephalic version.

\begin{tabular}{|c|c|c|c|c|c|}
\hline & & $\begin{array}{l}\text { Suspect } \\
\qquad(n\end{array}$ & $\begin{array}{l}\text { Breech } \\
\text { 4) }\end{array}$ & & \\
\hline & & & & & \\
\hline ECV received & & $\begin{array}{r}\text { Confirn } \\
167 \\
\text { Yes } \\
123(74 \%)\end{array}$ & $\begin{array}{l}\text { Breech } \\
\%)\end{array}$ & & $6 \%)$ \\
\hline $\begin{array}{l}\text { Success Rate } \\
\text { of ECV } \\
(n=123)\end{array}$ & $\begin{array}{c}\downarrow \\
\text { Successful } \\
48(39 \%)\end{array}$ & & & $\downarrow$ & $\downarrow$ \\
\hline $\begin{array}{l}\text { Presentation at } \\
\text { birth } \\
(n=166)\end{array}$ & $\begin{array}{c}\stackrel{\downarrow}{ } \\
\text { Cephalic } \\
47(98 \%) \\
\text { (Missing 1) }\end{array}$ & $\begin{array}{c}\stackrel{\downarrow}{\text { Cephalic }} \\
2(1 \%)\end{array}$ & $\begin{array}{c}\downarrow \\
\text { Breech } \\
73(99 \%)\end{array}$ & $\begin{array}{c}\text { Cephalic } \\
2(5 \%)\end{array}$ & $\begin{array}{c}\text { Breech } \\
42(95 \%)\end{array}$ \\
\hline $\begin{array}{l}\text { Mode of birth } \\
(n=162)\end{array}$ & $\begin{array}{c}\downarrow \\
\text { Vaginal } 43 \\
\text { Cesarean } 1\end{array}$ & $\stackrel{\downarrow}{\downarrow}$ Vaginal 2 & $\begin{array}{c}\downarrow \\
\text { Vaginal } 21 \\
\text { Cesarean } 51\end{array}$ & $\stackrel{\downarrow}{\downarrow}$ Vaginal 2 & $\begin{array}{c}\downarrow \\
\text { Vaginal } 7 \\
\text { Cesarean 35 }\end{array}$ \\
\hline & (Missing 3) & & (Missing 1) & & \\
\hline
\end{tabular}


Rijnders, M., Offerhaus, P., Dommelen, P. van, Wiegers, T., Buitendijk, S. Prevalence, outcome, and women's experiences of external cephalic version in a low-risk population. Birth: 2010, 37(2), 124-133

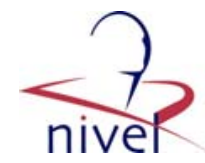

Table 1. Demographic Characteristics of Women with Suspected Breech Presentation in 46 Midwifery Practices in the Netherlands Between June 2007 and January 2008 in Comparison with a Reference Group $(n=304)$

\begin{tabular}{lccc}
\hline & \multicolumn{2}{c}{ Study Population } & $\begin{array}{c}\text { Reference Group } \\
\text { Characteristics }\end{array}$ \\
\cline { 2 - 4 } Percent or (Mean \pm SD)
\end{tabular}

$* \mathrm{p}<0.05$.

${ }^{a}$ Data from the Dutch Perinatal Registry of 174,581 pregnancies in 2005 ; $^{b}$ data from all women aged $15-44$ years in Statline Statistics Netherlands; ${ }^{c}$ no qualification or qualifications gained at the end of compulsory schooling; ${ }^{d}$ professional/qualifications gained after additional schooling.

$N A=$ not available $; E C V=$ external cephalic version

Table 2. Results of the (Multivariate) Logistic Regression Analyses on the (Independent) Effect of Factors on Pain During External Cephalic Version $(\mathbf{E C V} ; \boldsymbol{n}=\mathbf{9 5})$

\begin{tabular}{|c|c|c|c|c|}
\hline Variables & $\begin{array}{c}\text { No or Little Pain } \\
(\mathrm{n}=38) \\
\text { No. }(\%)\end{array}$ & $\begin{array}{l}\text { Significant Pain } \\
(\mathrm{n}=57) \\
\text { No. }(\%)\end{array}$ & OR $(95 \% C I)$ & Adjusted OR $(95 \% \mathrm{CI})$ \\
\hline \multicolumn{5}{|l|}{ Region } \\
\hline North & $18(64)$ & $10(36)$ & 1 & 1 \\
\hline Central & $13(33)$ & $26(67)$ & $3.5(1.2-9.6)$ & $4.0(1.2-12.6)$ \\
\hline South & $7(25)$ & $21(75)$ & $5.4(1.7-17.1)$ & $4.7(1.3-16.9)$ \\
\hline \multicolumn{5}{|c|}{ Successful ECV } \\
\hline Yes & $22(67)$ & $11(33)$ & 1 & 1 \\
\hline No & $16(26)$ & $46(64)$ & $6.3(2.5-16.2)$ & $5.3(1.9-14.7)$ \\
\hline \multicolumn{5}{|c|}{$\begin{array}{l}\text { Gestation at } \\
\text { diagnosis (wk) }\end{array}$} \\
\hline$\geq 36$ & $17(57)$ & $13(43)$ & 1 & 1 \\
\hline$<36$ & $21(32)$ & $44(68)$ & $2.7(1.1-6.5)$ & $2.3(0.8-6.5)$ \\
\hline
\end{tabular}


Rijnders, M., Offerhaus, P., Dommelen, P. van, Wiegers, T., Buitendijk, S. Prevalence, outcome, and women's experiences of external cephalic version in a low-risk population. Birth: 2010, 37(2), 124-133

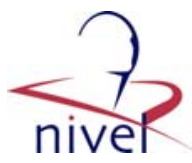

Table 3. Results of the Multivariate Ordinal Regression Analyses on the Impact of Factors on the Experience with External Cephalic Version $(\mathrm{ECV} ; \boldsymbol{n}=\mathbf{9 6})$

\begin{tabular}{|c|c|c|c|c|c|}
\hline Variables & $\begin{array}{c}\text { Very Positive } \\
\text { Experience } \\
(\mathrm{n}=15) \\
\text { No. }(\%)\end{array}$ & $\begin{array}{c}\text { Positive } \\
\text { Experience } \\
(\mathrm{n}=37) \\
\text { No. }(\%)\end{array}$ & $\begin{array}{l}\text { Neither Positive } \\
\text { nor Negative } \\
(\mathrm{n}=24) \\
\text { No. }(\%)\end{array}$ & $\begin{array}{l}\text { Negative } \\
\text { Experience } \\
(\mathrm{n}=20) \\
\text { No. }(\%)\end{array}$ & $\begin{array}{l}\text { Adjusted } \\
\text { OR }(95 \% C I)\end{array}$ \\
\hline \multicolumn{6}{|l|}{$\begin{array}{l}\text { Successful ECV } \\
(n=96)\end{array}$} \\
\hline Yes & $10(67)$ & $17(46)$ & $4(17)$ & $2(10)$ & 1 \\
\hline No & $5(33)$ & $20(54)$ & $20(83)$ & $18(90)$ & $1.6(0.7-3.0)$ \\
\hline \multicolumn{6}{|l|}{ Pain $(n=95)$} \\
\hline No (or little) & $14(93)$ & $22(61)$ & $2(9)$ & $0(0)$ & 1 \\
\hline Yes & $1(7)$ & $15(39)$ & $21(91)$ & $20(100)$ & $6.0(3.3-12.2)$ \\
\hline \multicolumn{6}{|l|}{$\begin{array}{l}\text { Fear during ECV } \\
(n=94)\end{array}$} \\
\hline No & $15(100)$ & $36(100)$ & $19(83)$ & $14(70)$ & 1 \\
\hline Yes & 0 & 0 & $4(17)$ & $6(30)$ & $2.7(1.1-6.0)$ \\
\hline \multicolumn{6}{|l|}{$\begin{array}{l}\text { Counseling caregiver } \\
(n=96)\end{array}$} \\
\hline Good & $15(100)$ & $34(92)$ & $23(96)$ & $16(80)$ & 1 \\
\hline $\begin{array}{l}\text { Bad or different } \\
\text { among caregivers }\end{array}$ & $0(0)$ & $3(8)$ & $1(4)$ & $4(20)$ & $1.3(0.5-3.3)$ \\
\hline
\end{tabular}

Notes: Thresholds: very positive experience, estimate -0.9 (95\% CI: -0.5 to 0.4); positive experience, estimate 1.8 (95\% CI: 1.1-2.4); no positive or negative experience, estimate 2.8 (95\% CI: 2.1-3.6). 